Federal Reserve Bank of New York

Staff Reports

\title{
The Effectiveness of Nonstandard Monetary Policy Measures: Evidence from Survey Data
}

\author{
Carlo Altavilla \\ Domenico Giannone
}

Staff Report No. 752

December 2015

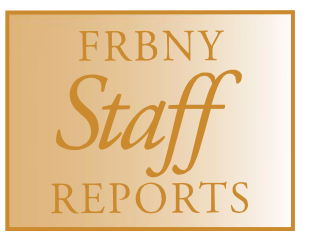

This paper presents preliminary findings and is being distributed to economists and other interested readers solely to stimulate discussion and elicit comments. The views expressed in this paper are those of the authors and do not necessarily reflect the position of the Federal Reserve Bank of New York or the Federal Reserve System. Any errors or omissions are the responsibility of the authors. 


\title{
The Effectiveness of Nonstandard Monetary Policy Measures: Evidence from Survey Data
} Carlo Altavilla and Domenico Giannone

Federal Reserve Bank of New York Staff Reports, no. 752

December 2015

JEL classification: E58, E65

\begin{abstract}
We assess the perception of professional forecasters regarding the effectiveness of unconventional monetary policy measures announced by the U.S. Federal Reserve after the collapse of Lehman Brothers. Using survey data collected at the individual level, we analyze the change in forecasts of Treasury and corporate bond yields around the announcement dates of nonstandard monetary policy measures. We find that professional forecasters expect bond yields to drop significantly for at least one year after the announcement of accommodative policies.
\end{abstract}

Key words: Survey of Professional Forecasters, large-scale asset purchases, quantitative easing, Operation Twist, forward guidance, tapering

Giannone: Federal Reserve Bank of New York (e-mail: domenico.giannone@ny.frb.org). Altavilla: European Central Bank (e-mail: carlo.altavilla@ecb.europa.eu). The authors thank Jonathan Wright and two anonymous referees for their helpful comments and suggestions. They also thank Manuel Arellano, Ciro Avitabile, Giacomo Carboni, Dean Croushore, István Kónya, Egon Zakrajsek, and seminar participants at the Bank of England, Queen Mary University of London, the CESifo Area Conference on Macro, Money, and International Finance, University of London Birkbeck, the CSEF-IGIER Symposium on Economics and Institutions, the Ghent Workshop on Empirical Macroeconomics, Cass Business School, and the Annual Congress of the European Economic Association. The views expressed in this paper are those of the authors and do not necessarily reflect the position of the European Central Bank, the Eurosystem, the Federal Reserve Bank of New York, or the Federal Reserve System. 


\section{Introduction}

Before the collapse of Lehman Brothers, monetary policy was typically implemented by setting the short-term interest rate. After the aggressive policy response that followed the collapse of Lehman Brothers, the short-term interest rate reached its zero lower bound (ZLB), hence preventing any possibility to provide additional stimulus to the economy through conventional operating instruments. Since then, the Federal Reserve's Federal Open Market Committee (FOMC) has systematically engaged in alternative strategies to support consumption and investment spending by making financial conditions more accommodative and exerting downward pressure on bond yields. In general, these policies have involved Large Scale Asset Purchases, such as Quantitative Easing and Maturity Extension Program, and Forward Guidance, i.e. the communication of the intended degree of future policy accommodation.

The effects of unconventional policies on yields of different financial assets have been evaluated by a large empirical literature using event study methodology. The general finding is that both Treasury and corporate bond yields dropped significantly in correspondence to the announcement and the implementation of such policy measures, e.g., Gagnon et al. (2011), Krishnamurthy and Vissing-Jorgensen (2011), Swanson (2011), Campbell et al. (2012), and Kool and Thornton (2012), Hamilton and Wu (2012), Del Negro et al. (2013). Event study methodology is a powerful tool for quantifying the immediate effect of policy communication and implementation but not for assessing the persistence of those effects. The working hypothesis of the event studies is that new information is immediately and permanently incorporated into the prices of financial asset (for a recent comprehensive discussion on event-study methodology see Gurkaynak and Wright, 2013).

We complement event studies by analyzing how agents update their expectations on yields of Treasury and corporate securities embedding different credit risk in response to the announcement of the non-standard policy measures. By analyzing market expectations for different forecasting horizons, we are able to assess not only the immediate effects of the non-standard policies but also the expected persistence of these effects.

We measure market expectations by using the Survey of Professional forecasts (SPF) conducted by the Federal Reserve Bank of Philadelphia (see Croushore, 1993). Near the middle of every quarter, the survey participants provide their forecasts of several variables for different forecasting horizons. We quantify the effects of policy announcements on forecasters' beliefs by examining how individual forecasters revise their predictions of bond yields. Focusing on the revisions of expectations allows us to isolate the unexpected component of bond rate changes. However, as the time window between two consecutive surveys is relatively wide, i.e. one quarter, many concurrent factors could influence the changes in expectations. We tackle this issue by controlling for the perceived changes in the current macroeconomic environment. Our empirical methodology is 
based on two identifying assumptions. First, professional forecasters believe that policy interventions can be transmitted immediately to bond yields, while they can affect the expectations for economic growth and inflation only after one quarter. Second, policy makers do not respond contemporaneously to changes of forecasters' beliefs about bond yields in the current quarter. Similar assumptions have been widely used in time series econometrics to identify exogenous changes of standard monetary policy actions (Sims, 1982; Bernanke and Mihov, 1998; Christiano, Eichembaum and Evans, 1999).

The paper is structured as follows. Section 2 summarizes the main policy actions adopted by the Federal Reserve in response to the financial crises and evaluate their effectiveness through an event study analysis. Section 3 quantifies the agents' beliefs regarding the impact of the unconventional policy measures on bond yields. Section 4 concludes.

\section{Non-standard measures at zero lower bound}

The events of interest are the announcements of non-standard monetary policy measures made by the Federal Reserve System after the collapse of Lehman Brothers.

On November 25, 2008, the FOMC announced its first quantitative easing program (QE1). On December 1, 2008, Chairman Bernanke stated that "Although conventional interest rate policy is constrained by the fact that nominal interest rates cannot fall below zero [...] the Fed could influence financial conditions [by purchasing] longer-term Treasury or agency securities on the open market in substantial quantities". By the end of this program in March 2010, the Fed had purchased $\$ 1.25$ trillion of mortgage-backed securities, $\$ 200$ billion of debt directly issued by the housing-related government-sponsored enterprises, and $\$ 300$ billion of longer-term Treasury securities.

In the second half of 2010, the FOMC announced a second program of quantitative easing (QE2), which consisted of purchasing a further $\$ 600$ billion of longer-term Treasury securities by the end of the second quarter of 2011 , at a pace of approximately $\$ 75$ billion per month.

On September 21, 2011, the FOMC announced a further round of unconventional measures. This program, officially named Maturity Extension Program (MEP), was also known as "Operation Twist" due to its similarities with a policy implemented in the early 1960s. ${ }^{1}$ The Federal Reserve committed to purchase, by the end of June 2012, $\$ 400$ billion of Treasury securities with remaining maturities of 6 years to 30 years and sell an equal amount of Treasury securities with remaining maturities of 3 years or less. On June 20, 2012, this program was extended to the end of 2012.

\footnotetext{
${ }^{1}$ See Modigliani and Sutch (1966, and 1967), and Swanson (2011).
} 
On September 13, 2012, the FOMC announced a third round of quantitative easing (QE3) consisting of "purchasing additional agency mortgage-backed securities at a pace of $\$ 40$ billion per month."2 Finally, on December 12, 2012, the FOMC announced additional purchases of longerterm Treasury securities initially at a pace of $\$ 45$ billion per month.

In addition to large-scale asset purchases, the FOMC's communications after the crisis have increasingly relied on forward guidance. Since the onset of the financial crisis, almost every FOMC statement makes explicit reference to the expected macroeconomic outlook, the future policy measures, as well as the likely future path of the short-term rate. The FOMC Statement of August 2011, for example, stated that "Committee currently anticipates that economic conditions [....] are likely to warrant exceptionally low levels for the federal funds rate at least through mid-2013." In its January and September 2012 statements, the FOMC revised its outlook for the federal funds rate by extending its expectations of the exceptionally low level at least through "late 2014" and "mid2015", respectively. On December 12, 2012, the FOMC indicated that a federal funds rate close to zero would remain appropriate at least as long as the unemployment rate remains above 6-1/2 per cent and inflation expectations continue to be well anchored.

Monetary policy became less accommodative during 2013 in response to a more positive economic outlook. The change in the degree of intended monetary policy accommodation began with the announcements on the tapering-off and downsizing of the Fed portfolio. On May 22, 2013, in his Testimony to the U.S. Congress, Chairman Bernanke hinted to a possible reduction in asset purchases in the next two FOMC meetings. On June 19, 2013, during his Press Conference, Chairman Bernanke stated that "if the incoming data are broadly consistent with this forecast, the Committee currently anticipates that it would be appropriate to moderate the monthly pace of purchases later this year." On December 18, 2013, the FOMC "decided to modestly reduce the pace of its asset purchases". More precisely, the monthly purchases of agency mortgage-backed securities and longer-term Treasury securities decreased from $\$ 40$ and $\$ 45$ billion to $\$ 35$ and $\$ 40$ billion, respectively. The reduction in the size of purchases continued till October 29, 2014, when the Fed announced that it would have stopped making large-scale asset purchases at the end of the month.

Based on these announcements we identify a set of twenty-three policy events summarized in the first two columns of Table 1. For the first round of Quantitative Easing (QE1), we consider the eight events, identified in Gagnon et al. (2011), including the initial announcement, the Chairman speech on December 1, 2010, and selected FOMC meetings that followed. For the second round of Quantitative Easing (QE2), we use the five events analyzed by Wright (2012), which include FOMC meetings and selected Chairman speeches. For Maturity Extension Program (MEP), we identify four events that include the official policy announcement (September 21, 2011) and the following

\footnotetext{
${ }^{2}$ Note that in the FOMC statement there was no indication of when QE3 would have ended.
} 
three FOMC meetings, when the Federal Reserve reiterates its intent to continue it. ${ }^{3}$ To make the results of the event study comparable with the one obtained when using the SPF, we have also included a policy announcement more related to a change in the approach to forward guidance on policy rates. More precisely, the intra-SPF period associated with the MEP includes the FOMC Statement of August 9, 2011 where an important change in the form of forward guidance (from open-ended to calendar-based guidance), and then implicitly on the form of monetary policy commitment going forward, was introduced. For the third round of Quantitative Easing (QE3), we identify two dates: the first one (August 22, 2012) corresponds to the release of the FOMC minutes of the July/August meeting, which provided the first signal that the Federal Reserve was considering the possibility of an additional round of Quantitative Easing; the second one (September 13, 2012) is the official announcement date of QE3.

Finally, to analyze the bond market reaction during the announcements of the tapering, we select three episodes: the announcement made on December 18, 2013, and two previous episodes that anticipated the possibility of reducing the pace of asset purchases (May 22, and June 19, 2013).

\section{INSERT TABLE 1 OVER HERE}

We measure the effect of non-standard monetary policies by employing event-study analysis (Gurkaynak and Wright, 2013) around the selected announcement dates. Specifically, we quantify the changes in the 10-year Treasury bond (constant-maturity), and the Moody's indexes of AAA and BAA corporate bond yields in a 2-day event window. ${ }^{4}$ Analyzing the impact of the nonstandard measures on yields of both Treasury and corporate bonds featuring different credit quality might help understand whether these measures affected financial instruments other than those directly purchased by the central bank.

Estimates are obtained by regressing the daily changes in selected bond yields on a set of eventdummies. We control for other factors that might have influenced the dynamic of the bond rates by including in the regression the surprise component of a large set of market-moving macroeconomic releases, defined as the standardized difference between the data released during the days of the event and the consensus forecasts collected immediately before the official data release. More specifically, the regression takes the following form:

\footnotetext{
3 We have not included the videoconference meeting of November 28, 2011, since it is related to international developments. In that unscheduled meeting, the Committee met to discuss a proposal to increase the Federal Reserve's temporary liquidity swap arrangements with foreign central banks in response to pressures in global financial markets.

${ }^{4}$ Data on interest rate are retrieved form FRED. The sovereign yields are Treasury Constant Maturity Rate. Data on corporate bond are from Moody's.
} 


$$
y_{t}=\sum_{j=1}^{k} \lambda_{j} D_{j, t}+\sum_{j=1}^{k} \vartheta_{j} D_{j, t-1}+\sum_{s=1}^{m} \delta_{s} N e w s_{s, t}+\varepsilon_{t}
$$

where $t$ indexes days, the dependent variable ( $\left.y_{t}\right)$ is the daily change in bond rates, which in turn are the 10-year Treasury bond yields, the AAA and BAA corporate bond yields. $D_{j, t}$ denotes a set of event-dummy variables each of them taking value one at the date of the selected policy announcement, and zero elsewhere. The vector $N e w s_{s, t}$ includes the surprise components of a large set of macroeconomic variables "s", such as non-farm payroll, retail sales consumer price index released during the day " $\mathrm{t}$ ". ${ }^{5}$ More specifically, if the macroeconomic indicator " $\mathrm{s}$ " is not released during day " $\mathrm{t}$ " the variable is set equal to zero. Otherwise, it is defined as the difference between the data released during the day " $\mathrm{t}$ " and the consensus forecasts collected up to immediately before the official data release.

The sum $\lambda_{j}+\vartheta_{j}$ gives the 2 -days effects ${ }^{6}$ of the policy announcement for each of the $\mathrm{k}=23$ events. Traditionally event-studies have not controlled for macroeconomic surprises. This correspond to the case where coefficients $\delta$ 's are set to zero. In this case, the effect of the announcement corresponds to the change in bond yields between the (end of the) day after the announcement and (the end of) the day before the announcement.

Estimates are obtained by Ordinary Least Squares and statistical significance is assessed by using heteroskedasticity robust standard errors. The sample period ranges from the beginning of January 2007 to the end of March 2014.

Columns 4, 6, and 8 of Table 1 report the results of the event study "controlled" for macroeconomic news. Estimates obtained without controlling for the macroeconomic news are reported in Columns 2, 5, and 7; we call those estimates "classical" because existing event studies have omitted to control for macroeconomic news.

The results indicate that non-conventional policies have had statistically significant and economically important effects on Treasury and corporate bonds. The first round of policies implemented immediately after the collapse of Lehman Brothers has been the most effective: the cumulated impact of QE1 resulted in a reduction of about one percentage point for the yields on 10-year Treasury bond and three-fourth of a percentage point for corporate bonds. The two following rounds of asset purchases programs had more muted but still significant effects: yields on Treasury bonds declined by a total of one-third (one-half) of a percentage point around the announcement dates of QE2 (MEP). Interestingly, even if QE2 and MEP only involved purchases

\footnotetext{
${ }^{5}$ The model includes a large set of market-moving macroeconomic variables for US as well as the ECB Main Refinancing Rate to account for possible spillovers from the announcements of the non-standard measures undertaken in the euro area. Data on 40 macroeconomic variables and the corresponding forecasts are retrieved from Bloomberg.

${ }^{6}$ Qualitative results are conformed when we focus on one-day effects, which are measured by $\lambda_{j}$.
} 
of Treasury securities, their announcements were associated with a significant decline of corporate bond yields by about one-fourth of percentage point. The last round of QE has produced less relevant effects on yields. The announcements related to the tapering-off of the Fed portfolio have been instead associated with a substantial increase in both Treasury and corporate bond yields. Overall, the results suggest that the unconventional measures have had a broad impact on the price of financial assets that ultimately resulted in a substantial contraction in the cost of market financing for the government and for firms.

The inclusion of macroeconomic surprises has marginal effects on the results. This is not surprisingly since we focus on important events whose effects are large and dominate macro news within the event window.

\section{Non-standard measures and forecasters beliefs}

In the previous Section, we have used the high-frequency event study methodology to quantify the immediate effect of policy announcements. In what follows, we complement that event study by examining the impact of the selected policy events on the predictions made by professional forecasters of Treasury and corporate bond yields at different horizons.

We use individual data collected by the Federal Reserve Bank of Philadelphia in the Survey of Professional Forecaster (SPF), which is a quarterly survey that includes expectations at different horizons for many macroeconomic indicators, including bond yields. ${ }^{7}$ Since the announcements of specific policies mostly fall between consecutive rounds of the survey, we can quantify their perceived effects by analyzing how individuals revise their forecasts between consecutive rounds of the survey. The last column of Table 1 reports the match of various policy measures with specific inter-SPF periods. The latter is identified by the exact date at which the forecasters participating in the SPF sent back their questionnaire. The announcements of specific unconventional policy that fall into these periods are shaded. It is evident that the policy events associated with a single policy mostly fall between consecutive rounds of the survey. A notable exception is QE1 for which the announcements went on for one year. In addition, some announcements associated with the MEP and Tapering fall outside the inter-SPF survey periods we select. This might create a possible distortion, especially for QE1 since we are omitting the FOMC announcement made in March 18, 2009, which, as documented in Section 2, had a big immediate impact. ${ }^{8}$

\footnotetext{
7 The survey started in the fourth quarter of 1968 and was first conducted by the American Statistical Association and the National Bureau of Economic Research. Then, the Federal Reserve Bank of Philadelphia took over the survey in the second quarter of 1990 (for details, see Croushore, 1993).

${ }^{8}$ To address this problem we could include additional inter-SPF periods. For QE1 we have considered the forecast revision between Q1 and Q2 2009 and results are significantly similar. For this reason, we have preferred to maintain the correspondence between single inter-SPF round and individual policy measures.
} 
The reliability of the match we use in the empirical analysis is confirmed by examining Google trends data. The volume of Google queries is used to provide indication on the general interest in each non-standard measure stemming from media discussions, economic release, and official communications. Figure 1 reports a normalized index of internet search queries of the terms "quantitative easing", "operation twist", 9 and "tapering" from the United States from January 2009 to March 2015. For each non-standard measure, the shaded area represents the corresponding evaluation period between the two selected SPF surveys. It is evident that the search intensity for the selected words peaks during the period considered in the analysis. This evidence supports our identification of the selected survey rounds.

\section{INSERT FIGURE 1 OVER HERE}

In order to measure the impact of policy measures on agents' beliefs we define forecast revisions as the difference between the forecasts for calendar quarter $t+h$, reported in the survey round of quarter $v=t$ and the forecast for the same period $(t+b)$ made in the forecast round of the previous quarter $v=t-1$.

$$
R z_{i, t}^{(h)}=z_{i, t+h \mid v=t}-z_{i, t+h \mid v=t-1} h=0, \ldots 3
$$

In other words, the forecast revision is defined as the difference between $h$ quarters ahead forecast reported in the survey of quarter $v=t$ and the $b+1$ quarters ahead forecasts made in the previous survey, conducted in the quarter $v=t-1$. Notice that the calendar quarter to which the forecast refers is kept fixed. What changes, instead, is the reporting period, and hence the information set of the professional forecasters. In absence of any news in the inter-SPF window forecast revisions are zero.

Figure 2 reports the consensus (i.e., the median across individual forecasters) and the crosssectional dispersions (summarized by selected quantiles) of the revisions of forecasts for the Treasury bonds yields. The vertical gridlines represent the quarters of interest for which we measure the effect of non-standard policies. For convenience, selected survey rounds will be denoted by the associated policy action: QE1 for 2009Q1, QE2 for 2010Q4, MEP for 2011Q4, QE3 for 2012Q3, and TAP (tapering) for $2013 Q^{3}$.

It is evident that, in spite of a substantial disagreement, forecasters collectively revised their predictions for the long-term interest rate in correspondence to the implementation and announcement of unconventional monetary policy measures. The revision was largest in

\footnotetext{
${ }^{9}$ We have searched for the "operation twist" instead of the official name of the policy because the media extensively used this name. When searching for "maturity extension program" there is not enough search volume to produce a report.
} 
correspondence to QE1 between November 2008 and February 2009 the expectations for government bond yields in the first quarter of 2009 declined on average by more than 100 basis points. Interestingly, the magnitude of the revisions is large also for forecasts at longer horizons. Revisions of similar magnitude at all horizons are also observed in correspondence to QE2, MEP and QE3. Around the announcement of the tapering-off of QE purchases we observe an upward revision of the forecasts (approximately 50 basis points).

\section{INSERT FUGURE 2 OVER HERE}

As already mentioned, by simply examining the change in forecasters' expectations before and after policy announcements, we cannot correctly assess the effect of the policy measures. During the inter-SPF periods associated with the announcement of monetary measures, forecasters receive other news that might influence their predictions for bond yields. Consequently, forecasters might revise their expectations to incorporate not only the effects of non-standard policies but also the effects of confounding factors that occurred in the inter-survey period. For example, downward forecast revisions of bond yields might be due to any news that is expected to reduce inflation or to generate an economic slowdown. We tackle this endogeneity issue by controlling for currentquarter revisions in the forecasts of inflation and growth.

Precisely, we estimate the following equation:

$$
R y_{i, t}^{(h)}=\sum_{j=1}^{k} \gamma_{j}^{(h)} Q_{t}^{j}+\boldsymbol{\beta}^{(h)} Z_{i, t}+\varepsilon_{i, t}^{(h)}
$$

where the dependent variable $R y_{i, t}^{(h)}$ is the forecast revision of the yields on different bonds, the 10year Treasury, the AAA and BAA corporate. The superscript $b(b=0, \ldots, 3)$ indicates the forecast horizons; the subscript $i(i=1, \ldots, n)$ denotes individual forecasters, the subscript $j(j=2009 q 1,2010 q 4$ and 2011q4, 2012q4, 2013q3) denotes the end of inter-SPF period that we matched with different rounds of policy. The regressors $Q_{t}^{j}$ are dummy variables that take value one at the quarter of policy event, and zero otherwise. The coefficients $\gamma_{j}^{(h)}$ measure the average h-quarter ahead effect of the “j”-th round of non-standard policy on bond yields " $y$ ". The effect expected by each individual forecaster is measured as $\gamma_{j}^{(h)}+\varepsilon_{i, t_{j}}^{(h)}$ for $i=1, \ldots, n$, where $\mathrm{t}_{\mathbf{j}}$ is the relevant inter-SPF quarter.

The vector $Z_{i, t}=\left(R g_{i, t}^{(0)}, R \pi_{i, t}^{(0)}, R r_{i, t}^{(0)}\right)$ contains the revision of current quarter forecasts for real GDP growth (g), CPI inflation $(\pi)$, and the 3-month Treasury bill rate (r). As stated above, the inclusion of forecast revisions of inflation and growth aims at netting out the effects of other factors, unrelated to unconventional policy, influencing at the same time the expectations about bond yields and the macroeconomic outlook. By including the short-term interest rate in the set of 
controls, we net out the effects of standard monetary policy. The constant term is not included in the regression since forecasters are expected not to persistently revise their predictions in the same direction. The error term $\varepsilon_{i, t}^{(h)}$ represents the change in the expectations of bond yields that are not accounted for by current quarter developments in prices, output and the short-term interest rate.

The estimates $\gamma_{j}^{(h)}$ are unbiased if the regression error $\varepsilon_{i, t}^{(h)}$ satisfies conditional mean independence $^{10}$, that is $E\left(\varepsilon_{i, t}^{(h)} \mid Q_{t}^{j}, Z_{i, t}\right)=E\left(\varepsilon_{i, t}^{(h)} \mid Z_{i, t}\right)$. This condition is satisfied if: 1) the controls $Z_{i, t}$ are not affected by the unconventional policies; and 2) the unconventional policies are exogenous, $E\left(\varepsilon_{i, t}^{(h)} \mid Q_{t}^{j}\right)=0$. The first assumption requires that current-quarter expectations for GDP growth, inflation and the short-term interest rate can change in response to confounding factors but not in response to the announcement of non-standard policy. The second assumption requires that the implementation decision and the timing of policy are not related to current quarter changes in beliefs about bond yields. The assumptions that the effects of policy on the real economy is delayed and that policy decisions are not affected by current quarter variations of long term bond yields are equivalent to the recursive identification scheme used in Structural Vector Autoregressions to identify standard policy (for recent studies see Bernanke et al., 2005; Giannone, et al., 2015).

Notice that only current-quarter macro forecasts are included as independent variables. We do not control for longer-horizon macro forecasts in order to avoid issues arising from simultaneity of expected bond yields and expected longer-run GDP growth and inflation.

It is important to notice that our methodology is designed to quantify the effects of announcements on survey expectations of yields. This contrasts with other papers that look at effects of announcements on actual yields (see Wright 2012). Focusing on expectations rather than on actual outcomes allows us to measure separately the dynamic effects of each individual announcement. On the other hand, the cost of our approach is that Survey Expectations might in principle be distorted by herding behavior, strategic considerations and limited ability of forecasters to process incoming information (see Marinovic, 2013). Additional distortions might be due to informational rigidities (see Coibion and Gorodnichenko, 2012). In practice, however, the predictions of professional forecasters are rather accurate and compare well with institutional forecasts (such as those of the Federal Reserve Staff, see D'Agostino and Whelan, 2008) and with the forecasts produced by state-of-the-art econometric models (Del Negro and Schorfheide, 2012; Giannone et al., 2008).

The sample period goes from the first quarter of 1996 to the first quarter of 2015. The panel is unbalanced because of the entry and exit of forecasters in the panel. The expectations on all

\footnotetext{
${ }^{10}$ See Stock and Watson, 2011, Chapter 13.
} 
variables of interest are available over the entire sample. The only exception is the BAA-rated corporate bond yields that were included in the survey only since 2010Q1. The model is estimated by Ordinary Least Squares (OLS). ${ }^{11}$

The estimates of $\hat{\gamma}_{i, t}$ from equation (2) are reported in columns (2), (4), and (6) of Table 2. For each policy event and forecasting horizon, the table reports the revision of bond yields forecasts in correspondence to the various policy announcements. For symmetry with the event-study of the previous section, in columns (1), (3), and (5) of Table 2 we also report the results of a noncontrolled event-style regression, whereas equation (2) is estimated by including only the five policy-related dummies as independent variables. The distribution of the effects on the beliefs of individual forecasters, i.e. $\hat{\gamma}_{j}^{(h)}+\hat{\varepsilon}_{i, t_{j}}^{(h)}$, is plotted in Figure 3 using box-and-whisker diagrams (also known as box-plots).

\section{Insert Table 2 over Here}

\section{Insert Figure 3 over Here}

Results indicate that unconventional monetary policies have effectively influenced market expectations. Those policies have induced professional forecasters to significantly revise their expectations regarding government and corporate bond yields, at all horizons. On average, professional forecasters expected government bond yields to drop immediately by 55, 66, 84 and 56 basis points, in response to the announcements of QE1, QE2, MEP and QE3, respectively. The announcement of Tapering was instead associated with 56 basis point increase. The revisions of current quarter predictions have similar orders of magnitude to the effects of actual yields estimated in Section 2 using high-frequency event studies. For example, the immediate impact of Treasury Bonds cumulate during the inter-SPF survey period was a decline of about 50 basis points. The only exception is the MEP, for which we estimate a drop that is larger than the drop in correspondence of the announcements. ${ }^{12}$ Interestingly, longer horizons forecasts are revised by a similar order of magnitude, indicating that policy is expected to last for one year in most cases. This result is in line with the efficient market hypothesis that predicts that new information is priced immediately with no delayed effects or reversal. ${ }^{13}$

\footnotetext{
${ }^{11}$ We perform alternative estimates to accommodate for parameter's heterogeneity. We estimate equation (2) by mean-group, and fixed effects. We also consider alternative set of controls. Results reported in the Appendix are broadly unchanged.

${ }^{12} \mathrm{~A}$ possible explanation for this findings can be related to the influence that the public debt-ceiling crisis of early August 2011 might have had on the forecasts of bond yields made by professional forecasters.

${ }^{13}$ The evidence of persistent effects of unconventional monetary policies on bond yields is in contrast with Wright (2012) who finds that the effects of these policies is short lived. Understanding the differences in the results is difficult. Wright (2012) the analysis is implicitly based on the revisions of model-based, rather than judgmental, forecasts. In addition, Wright (2012) does not quantify the effects of each single round of policy
} 
The accommodative policies were expected to exert a significant downward pressures not only on government but also on corporate bonds. The magnitude of the change in the expectations of the AAA-rated bonds is comparable with the one of the government bonds. The impact on BAA-rated bonds, instead, is perceived to be more muted. This indicates that the announcements of nonstandard measures not only reduced the yields on the assets directly purchased by the Fed, but also spilled over into the yields of other assets.

By comparing results obtained with and without controlling of the current quarter revisions of forecasts for growth, inflation and the short-term interest rate, it is evident that the bias due to the omission is sizable for the first round of Quantitative Easing, but not for the subsequent rounds of unconventional policy. This suggests that the non-standard policy announcements are important events whose effects are large and dominate macroeconomic news within the selected inter-SPF period. ${ }^{14}$

From the inspection of Figure 3 it is also evident the substantial heterogeneity of beliefs among forecasters regarding the size of the expected policy effect. Disagreement tends to widen with the horizon, indicating that there is more disagreement for the effects of policy at longer horizons. There is some weak evidence that disagreement tends to decrease as more unconventional policies took place. This reduction is probably associated with the fact that more observations about the effects of policy become available to markets, which made them learned the effects of those policies and the commitment of the Federal Reserve in pursuing them. In addition, the reduced disagreement is also associated with a more aggressive forward guidance policy. In particular, forecasters tend to agree more on the effects of the event we label QE3 when the FOCM also announced a more aggressive forward guidance by postponing the likely timing of the lift-off, and in the event we label FG, between mid-November 2012 and mid-January 2013, when the Federal Reserve moved to state-contingent forward guidance. A similar pattern of reduction of disagreement has been highlighted for short maturities by Engen et al. (2014) and Andrade et al. (2014).

Overall, the results suggest that the non-standard measures effectively and persistently influenced market expectations. Importantly, the measures have influenced the expectations of the professional forecasters also on financial assets not directly purchased by the Fed.

separately but their average effects.

${ }^{14}$ Not surprisingly qualitative results remain unchanged when we include as additional controls the surprise component of all the market moving macroeconomic data released during the inter-SPF quarter. See Appendix for details. 


\section{Conclusions}

We have estimated the perceived effects of unconventional monetary policy measures on longterm Treasury bond rates and on yields of corporate securities with different credit rating by analyzing the revisions of predictions of professional forecasters around the announcement of policy decisions. The results indicate that the non-standard measures effectively and persistently influenced market expectations: professional forecasters expect the bond yields to drop significantly in response to the accommodative actions undertaken by the FOMC in the aftermath of the financial crisis. The drop is also estimated to be persistent, lasting for at least one year. The magnitude of the drop broadly coincides with the observed change in bond yields in the few days surrounding the most important policy announcements. This result indicates that, in line with the predictions of the efficient-market hypothesis, the bulk of the information regarding the stance of monetary policy has been priced into bond markets immediately by market participants.

Interestingly, the compression of yields of Treasury securities and corporate bonds featuring different credit rating in correspondence to the announcement of accommodative policies suggest that these measures also affected financial instruments other than those purchased by the central bank and helped create a favorable environment for long-term funding. 


\section{References}

Andrade, Philippe, Gaetano Gaballo, Eric Mengus and Benott Mojon (2014): Forward Guidance and Heterogeneous Beliefs, Banque de France, mimeo.

Banbura, Marta, Domenico Giannone and Lucrezia Reichlin (2010) Large Bayesian Vector Autoregressions, The Journal of Applied Econometrics, vol. 25(1), pages 71-92.

Bernanke, Ben S., Jean Boivin and Piotr S. Eliasz (2005) Measuring the Effects of Monetary Policy: A Factor-augmented Vector Autoregressive (FAVAR) Approach, The Quarterly Journal of Economics, vol. 120(1), pages 387-422.

Bernankem Ben S. and Ilian Mihov (1998) Measuring Monetary Policy, The Quarterly Journal of Economics, MIT Press, vol. 113(3), pages 869-902.

Campbell, Jeffrey R., Charles L. Evans, Jonas D.M. Fisher, and Alejandro Justiniano (2012): Macroeconomic Effects of FOMC Forward Guidance, Brookings Papers on Economic Activity, Spring issue, pages $1-54$

Christiano, Lawrence J., Martin Eichenbaum, and Charles L. Evans, (1999): Monetary policy shocks: What have we learned and to what end?, in J. B. Taylor \& M. Woodford (ed.), Handbook of Macroeconomics, vol. 1, chapter 2, pages 65-148.

Coibion Olivier and Yuriy Gorodnichenko (2012) What Can Survey Forecasts Tell Us about Information Rigidities?, Journal of Political Economy, vol. 120(1), pages 116 - 159.

Croushore, Dean (1993) Introducing: the survey of professional forecasters, Business Review, Federal Reserve Bank of Philadelphia, Nov. issue, pages 3-15.

D'Agostino, Antonello \& Karl Whelan (2008) Federal Reserve Information During the Great Moderation, Journal of the European Economic Association, vol. 6(2-3), pages 609-620.

D'Amico, Stefania, and Thomas B. King. (2013) Flow and Stock Effects of Large-Scale Treasury Purchases, Journal of Financial Economics, vol. 108, pages 425-448

Del Negro, Marco, and Frank Schorfheide (2012) DSGE Model-Based Forecasting, in the Handbook of Economic Forecasting Vol. II, edited by G. Elliott and A. Timmerman, Elsevier.

Del Negro, Marco, Marc Giannoni and Christina Patterson (2013) The forward guidance puzzle, Federal Reserve Bank of New York, Staff Reports 574.

Engelberg, Joseph, Manski Charles F., and Williams Jared (2009) Comparing the Point Predictions and Subjective Probability Distributions of Professional Forecasters, Journal of Business \& Economic Statistics, vol. 27, pages 30-41.

Engelberg, Joseph, Manski Charles F., and Williams Jared (2011) Assessing the temporal variation of macroeconomic forecasts by a panel of changing composition, Journal of Applied Econometrics, vol. 26, pages 1059-1078.

Engen, Eric M.,Thomas Laubach, and David L. Reifschneider (2015) The Macroeconomic Effects of the Federal Reserve's Unconventional Monetary Policies, Finance and Economics Discussion Series 2015-5, Board of Governors of the Federal Reserve System (U.S.).

Faust, Jon \& Rogers, John H. \& Wang, Shing-Yi B. \& Wright, Jonathan H. (2007)"The highfrequency response of exchange rates and interest rates to macroeconomic announcements," Journal of Monetary Economics, vol. 54(4), pages 1051-1068.

Gagnon, Joseph, Matthew Raskin, Julie Remasche, and Brian Sack (2011), Large-Scale Asset Purchases by the Federal Reserve: Did They Work?, Economic Policy Review, Federal Reserve Bank of New York, May issue, pages 41-59. 
Gagnon, Joseph, Matthew Raskin, Julie Remasche, and Brian Sack (2011) The Financial Market Effects of the Federal Reserve's Large-Scale Asset Purchases, International Journal of Central Banking, vol. 7, pages 3-43.

Giannone, Domenico, Michele Lenza and Giorgio Primiceri (2015) Prior Selection for Vector Autoregressions, Review of Economics and Statistics, vol. 92(2), pages 436-451.

Giannone, Domenico, Lucrezia Reichlin and David Small (2008) Nowcasting: The real-time informational content of macroeconomic data, Journal of Monetary Economics, vol. 55(4), pages 665676.

Gurkaynak, Refet S., Brian P. Sack, and Eric T. Swanson (2007) Market-Based Measures of Monetary Policy Expectations, Journal of Business and Economic Statistics, vol. 25, pages 201-212.

Gurkaynak, Refet S., and Jonathan H. Wright (2013) Identification and Inference Using Event Studies, Manchester School, vol. 81, pages 48-65.

Hamilton, James D., and Jing Cynthia Wu (2012) The Effectiveness of Alternative Monetary Policy Tools in a Zero Lower Bound Environment, Journal of Money, Credit, and Banking, vol. 44, pages 3-46.

Kool, Clemens J.M., and Daniel L. Thornton (2012) How effective is Central Bank Forward Guidance, Federal Reserve Bank of St. Louis, Working Paper N. 2012-063A

Krishnamurthy, Arvind and Annette Vissing-Jorgensen (2011). The Effects of Quantitative Easing on Interest Rates: Channels and Implications for Policy, Brookings Papers on Economic Activity, Fall issue, pages 215-287.

Lahiri Kajal and Xuguang Sheng (2010) Measuring forecast uncertainty by disagreement: The missing link, Journal of Applied Econometrics, vol. 25, pages 514-538.

Leeper Eric M., Christopher A. Sims and Tao Zha, 1996. "What Does Monetary Policy Do?," Brookings Papers on Economic Activity, vol. 27(2), pages 1-78.

Marinovic, Iván, Ottaviani, Marco, Sørensen, Peter Norman (2013): Forecasters' Objectives and Strategies, Handbook of Economic Forecasting. ed. / Graham Elliott; Allan Timmermann. Vol. 2B North-Holland, p. 689-720 (Handbooks in Economics).

Modigliani, Franco and Richard Sutch (1966) Innovations in Interest Rate Policy, American Economic Review, vol. 52, pages 178-97.

Modigliani, Franco and Richard Sutch (1967) Debt Management and the Term Structure of Interest Rates: An Empirical Analysis of Recent Experience, Journal of Political Economy, vol. 75, pages 569-89.

Pesaran, M.H. and R. Smith (1995) Estimation of Long-Run Relationships from Dynamic Heterogeneous Panels, Journal of Econometrics, vol. 68, pages 79-114.

Sims Christopher A., (1982) Policy Analysis with Econometric Models, Brookings Papers on Economic Activity, Economic Studies Program, vol. 13, pages 107-164.

Stock, James H. and Mark W. Watson (2011), Introduction to Econometrics (3rd ed.), Boston: Addison Wesley.

Swanson Eric T. (2011) Let's Twist Again: A High-Frequency Event-Study Analysis of Operation Twist and Its Implications for QE2, Brookings Papers on Economic Activity, pages 151-188.

Uhlig, Harald, (2005) What are the effects of monetary policy on output? Results from an agnostic identification procedure, Journal of Monetary Economics, vol. 52(2), pages 381-419.

Wright Jonathan H. (2012) What does Monetary Policy do to Long-Term Interest Rates at the Zero Lower Bound?, Economic Journal, vol. 122, pages F447-F466. 
Figure 1: Google Trends search volume index - weekly data
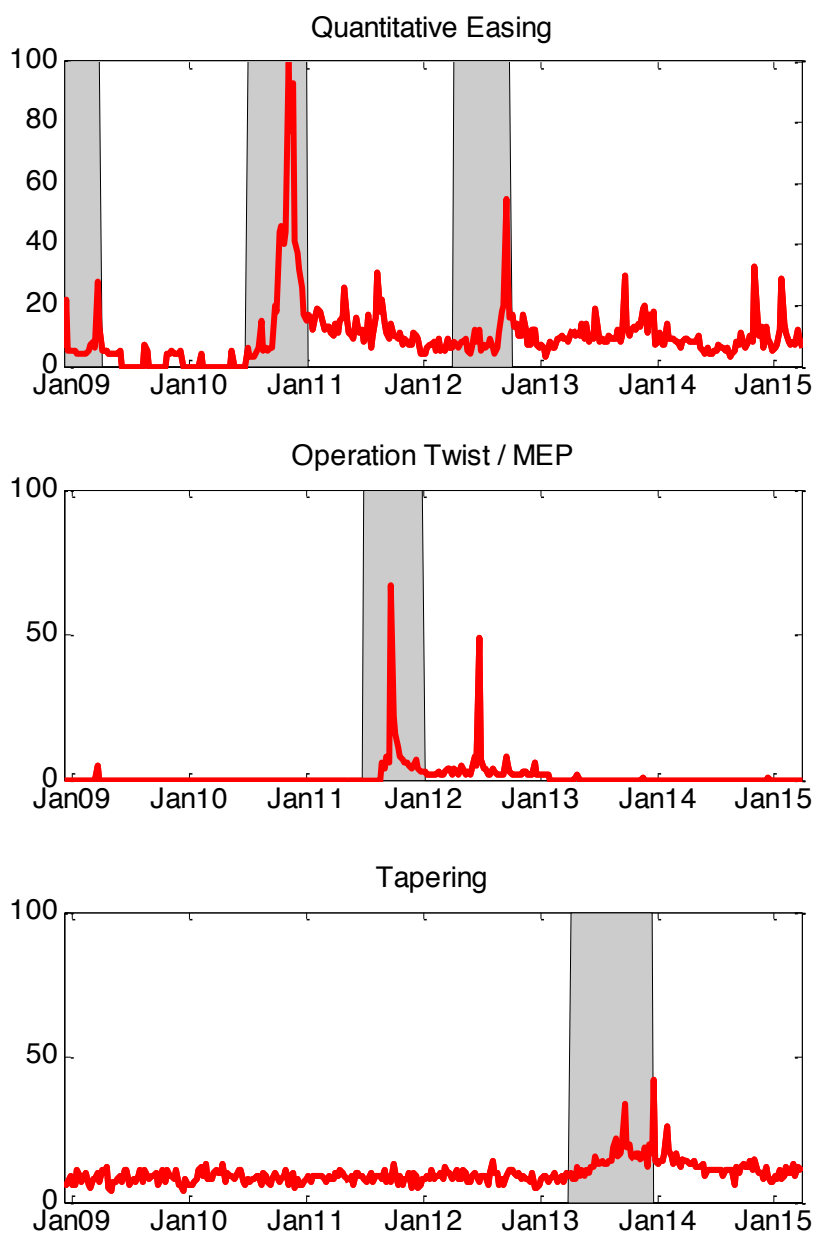

Note: The figure reports the Google Trends count of Internet search queries of the terms "quantitative easing", "operation twist", and "tapering" from the United States from January 2009 to March 2015. Data are scaled to the maximum search traffic for the specific term (represented as 100) during the time period from January 2009 to March 2015 in the United States. The shaded areas represent the evaluation periods for the five quarters of interest (i.e., 2009:1, 2010:4, 2011:4, 2012:3, and 2013:3). 
Figure 2: Change in the 10-year Treasury bond forecasts
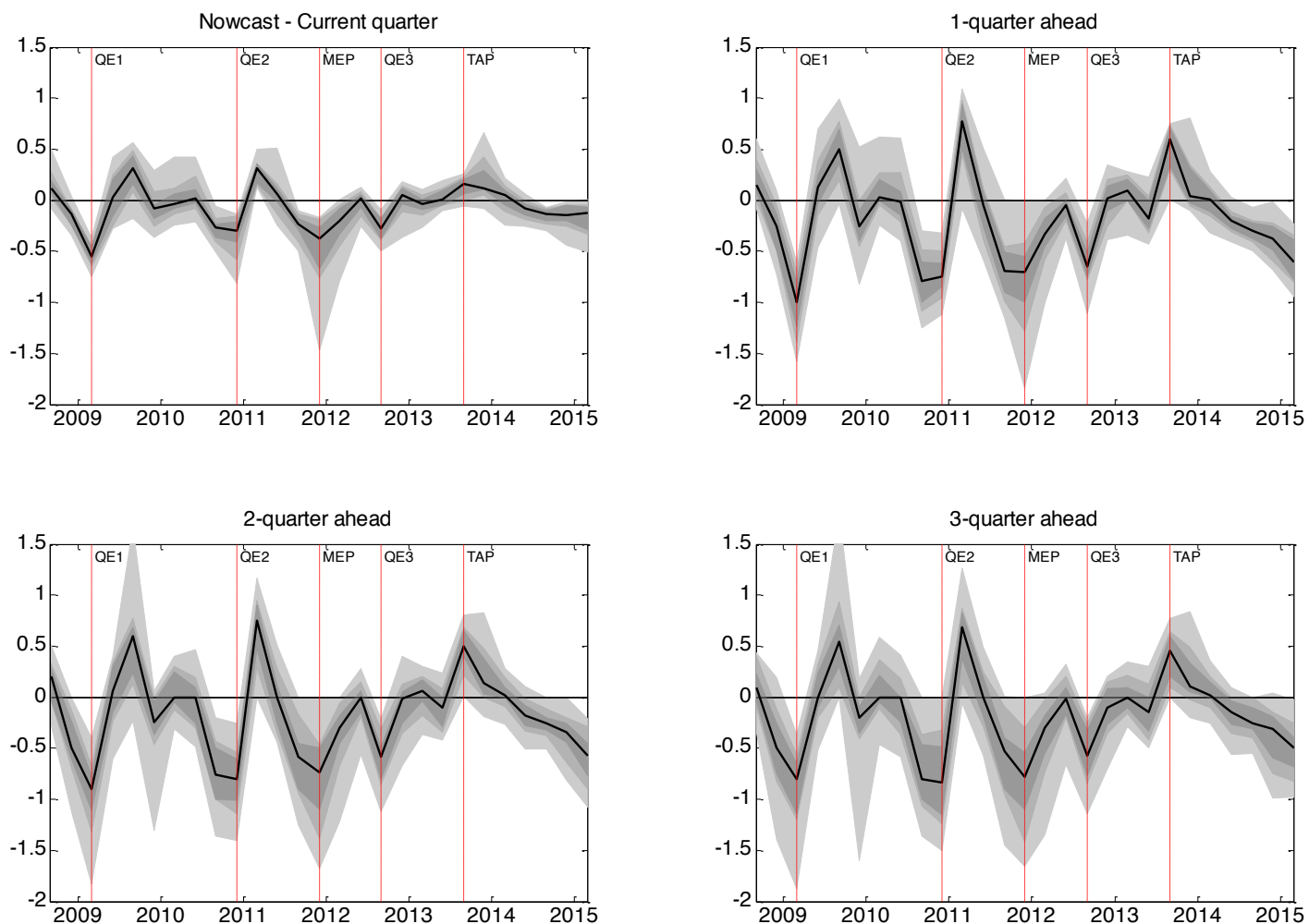

Note: For each quarter from 2008:1 to 2015:1, the figure reports the distribution of forecast revisions across panelists. The solid black line that goes through the areas is the median of the forecasters' distribution for each quarter. The shaded areas comprise $50 \%, 68 \%$ and $90 \%$ of the distribution. The vertical gridlines represent the announcement dates of the quarters of interest (i.e., 2009:1, 2010:4, 2011:4, 2012:3, and 2013:3). 
Figure 3: Cross-sectional distribution of the effect of non-standard measures on T-Bond

10-year Treasury Bond

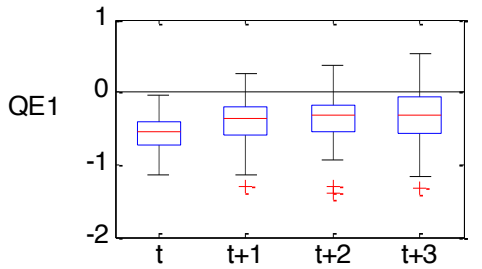

QE2

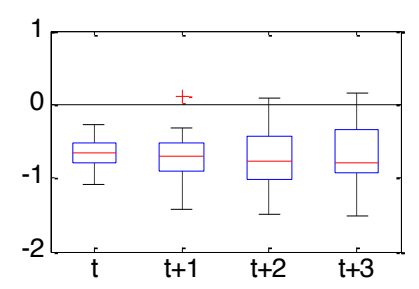

MEP

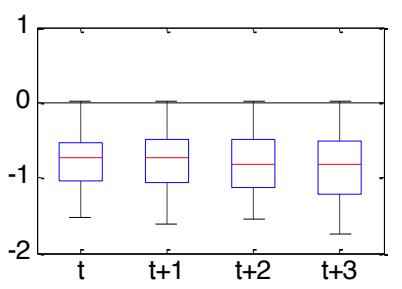

QE3
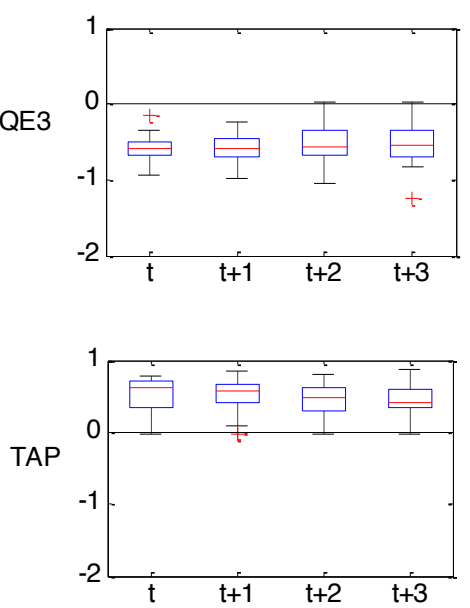

AAA Bond
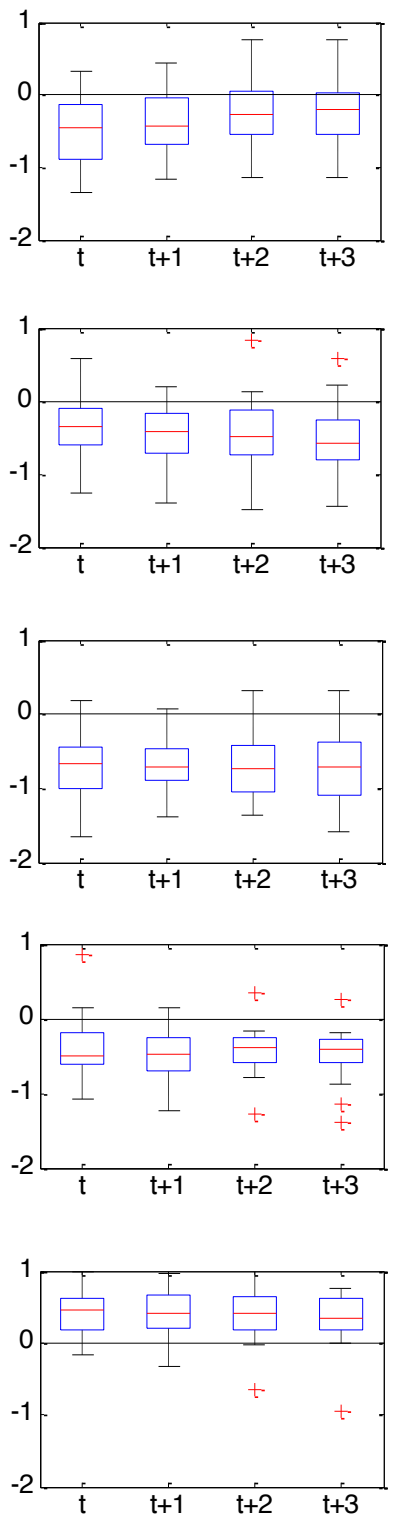
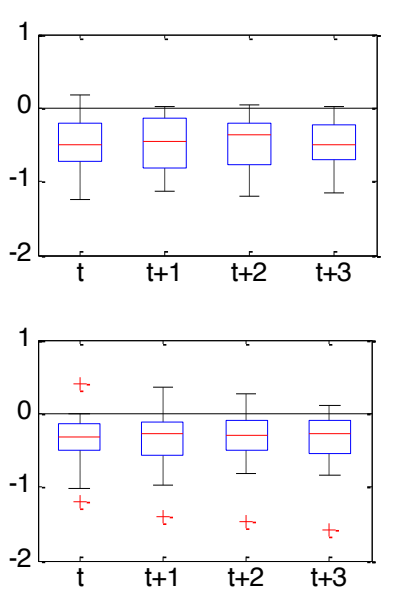

BAA Bond
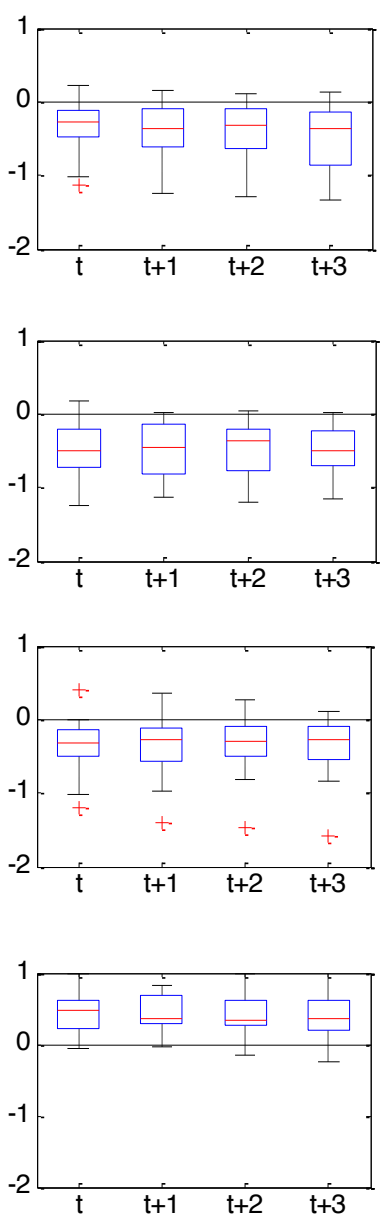

Note: The figure reports the distribution of the individual-specific coefficients of the expected effect of the non-standard monetary policy, which was retrieved from the second step of the estimation procedure. These graphs visualise the interquartile ranges (the box), the averages (the line inside the box), the maximum and the minimum values (the whisker), and the outliers (given a maximum whisker length "w", points are detected as outliers if they are larger than $\mathrm{q}_{3}+\mathrm{w}^{*}\left(\mathrm{q}_{3}-\mathrm{q}_{1}\right)$ or smaller than $\mathrm{q}_{1}-\mathrm{w}^{*}\left(\mathrm{q}_{3}-\mathrm{q}_{1}\right)$, where $\mathrm{q}_{1}$ and $\mathrm{q}_{3}$ are the $25^{\text {th }}$ and $75^{\text {th }}$ percentiles, respectively). 
Table 1: Changes in Treasury and Corporate yields around policy event dates

\begin{tabular}{|c|c|c|c|c|c|c|c|c|}
\hline \multirow[t]{2}{*}{ Date } & \multirow[t]{2}{*}{ Policy Event } & \multicolumn{2}{|c|}{ 10-year Treasury Bond } & \multicolumn{2}{|c|}{ AAA Corporate Bond } & \multicolumn{2}{|c|}{ BAA Corporate Bond } & \multirow[t]{2}{*}{ Deadline for SPF } \\
\hline & & Classical & Controlled & Classical & Controlled & Classical & Controlled & \\
\hline \multicolumn{9}{|c|}{ Quantitative Easing 1} \\
\hline Nov. 252008 & LSAP announcement & -34 & -30 & -18 & -17 & -17 & -15 & \\
\hline Dec. 12008 & Chairman Speech & -27 & -24 & -19 & -18 & -10 & -9 & 2008:4 (Nov. 18) \\
\hline Dec. 162008 & FOMC meeting & -33 & -25 & -25 & -23 & -23 & -20 & 2009:1 (Feb. 10) \\
\hline Jan. $\quad 282009$ & FOMC meeting & 30 & 33 & 26 & 29 & 5 & 7 & \\
\hline Sep. 232009 & FOMC meeting & -7 & -7 & -8 & -9 & -7 & -7 & \\
\hline Nov. 42009 & FOMC meeting & 6 & 6 & 2 & 2 & 0 & 0 & \\
\hline & & $-116^{* * *}$ & $-97^{* * *}$ & $-86 * * *$ & $-76^{* * *}$ & $-87^{* * *}$ & $-76^{* * *}$ & \\
\hline \multicolumn{9}{|c|}{ Quantitative Easing 2} \\
\hline Aug. 102010 & FOMC meeting & -15 & -13 & -8 & -7 & -6 & -6 & \\
\hline Nov. 32010 & FOMC meeting & -13 & -13 & -8 & -8 & -10 & -11 & \\
\hline & & $-36^{* *}$ & $-38^{* *}$ & $-24^{* *}$ & $-25^{* *}$ & $-25^{* *}$ & $-27^{* *}$ & \\
\hline \multicolumn{9}{|c|}{ Maturity Extension Program } \\
\hline Aug. 92011 & FOMC meeting & -20 & -20 & -16 & -16 & -6 & -6 & 2011:3 (Aug. 08) \\
\hline Sep. 212011 & FOMC meeting & -23 & -25 & -9 & -11 & 0 & -2 & 2011:4 (Nov. 08) \\
\hline Nov. 22011 & FOMC meeting & 7 & 15 & 6 & 11 & 2 & 6 & \\
\hline Dec. 132011 & FOMC meeting & -11 & -10 & -6 & -5 & -6 & -4 & \\
\hline Jan. 252012 & FOMC meeting & -13 & -14 & -9 & -9 & -14 & -15 & \\
\hline & & $-60 * * *$ & $-54^{* * *}$ & $-35 * * *$ & $-29 * * *$ & $-24 * * *$ & $-22^{* * *}$ & \\
\hline \multicolumn{9}{|c|}{ Quantitative Easing 3} \\
\hline Aug. 222012 & FOMC meeting & -14 & -13 & -9 & -8 & -10 & -9 & 2012:3 (Aug. 07) \\
\hline
\end{tabular}

Note: the controlled event study refer to a regression model where the daily changes in bond yields are regressed on a set of event dummies and the surprise component of a large set of market-moving macroeconomic variables. The variables included in the estimation are: ECB main refinancing rate, ADP employment change, change in nonfarm payrolls, Chicago purchasing manager consumer confidence index, continuing claims, CPI ex food and energy, CPI, current account balance, durable goods orders, durables ex transportation, existing home sales, factory orders, FOMC rate decision, GDP annualized, GDP price index, housing starts, import price index, industrial production, initial jobless claims, ism manufacturing, ISM non-manf. composite, Markit US manufacturing PMI, monthly budget statement, new home sales, PCE core, pending home sales, personal income, personal spending, Philadelphia FED business outlook, PPI ex food and energy, PPI final demand, retail sales advance, retail sales ex auto, Richmond FED manufact. index, S\&P/caseshiller 20-city index, trade balance, $\mathrm{U}$. of Michigan sentiment, unemployment rate, and wholesale inventories. Results of the event-study are based on a 2-day event window. Newey-West standard errors are used in the estimation. *, $* *$, and $* * *$ denote F-test significance of abnormal returns at $10 \%, 5 \%$, and $1 \%$, respectively. 
Table 2: Effect of non-standard measures on bond yields

\begin{tabular}{|c|c|c|c|c|c|c|}
\hline & \multicolumn{2}{|c|}{ 10-year Treasury Bond } & \multicolumn{2}{|c|}{ AAA Corporate Bond Yield } & \multicolumn{2}{|c|}{ BAA Corporate Bond Yield } \\
\hline & (1) & (2) & (3) & (4) & (5) & (6) \\
\hline \multicolumn{7}{|l|}{ current-quarter } \\
\hline Quantitative Easing 1 & $-1.02 * * *$ & $-0.55^{* * *}$ & $-0.68 * * *$ & $-0.45^{* * *}$ & - & - \\
\hline Quantitative Easing 2 & $-0.72 * * *$ & $-0.66^{* * *}$ & $-0.39 * * *$ & $-0.37 * * *$ & $-0.41 * *$ & $-0.34 * * *$ \\
\hline Maturity Extension Program & $-0.85^{* * *}$ & $-0.84 * * *$ & $-0.70^{* * *}$ & $-0.69 * * *$ & $-0.52^{* * *}$ & $-0.49 * * *$ \\
\hline Quantitative Easing 3 & $-0.64 * * *$ & $-0.58^{* * *}$ & $-0.42 * * *$ & $-0.40^{* * *}$ & $-0.42 * * *$ & $-0.36^{* * *}$ \\
\hline Tapering & $0.56^{* * *}$ & $0.56^{* * *}$ & $0.42^{* * *}$ & $0.42^{* * *}$ & $0.42^{* * *}$ & $0.43^{* * *}$ \\
\hline \multicolumn{7}{|l|}{ 1-quarter-ahead } \\
\hline Quantitative Easing 1 & $-0.97 * * *$ & $-0.41 * * *$ & $-0.63 * * *$ & $-0.31 * *$ & - & - \\
\hline Quantitative Easing 2 & $-0.78^{* * *}$ & $-0.72 * * *$ & $-0.51 * * *$ & $-0.48^{* * *}$ & $-0.48^{* * *}$ & $-0.41 * * *$ \\
\hline Maturity Extension Program & $-0.85^{* * *}$ & $-0.84 * * *$ & $-0.67 * * *$ & $-0.66^{* * *}$ & $-0.51 * * *$ & $-0.47 * * *$ \\
\hline Quantitative Easing 3 & $-0.64 * * *$ & $-0.58^{* * *}$ & $-0.45^{* * *}$ & $-0.42 * * *$ & $-0.43 * * *$ & $-0.37 * * *$ \\
\hline Tapering & $0.54 * * *$ & $0.55^{* * *}$ & $0.40^{* * *}$ & $0.41 * * *$ & $0.40^{* * *}$ & $0.41 * * *$ \\
\hline \multicolumn{7}{|l|}{ 2-quarter-ahead } \\
\hline Quantitative Easing 1 & $-0.92^{* * *}$ & $-0.35^{* * *}$ & $-0.57 * * *$ & $-0.22 * *$ & - & - \\
\hline Quantitative Easing 2 & $-0.78^{* * *}$ & $-0.71 * * *$ & $-0.51 * * *$ & $-0.48 * * *$ & $-0.47 * * *$ & $-0.39 * * *$ \\
\hline Maturity Extension Program & $-0.88^{* * *}$ & $-0.87 * * *$ & $-0.69^{* * *}$ & $-0.68 * * *$ & $-0.54 * * *$ & $-0.49 * * *$ \\
\hline Quantitative Easing 3 & $-0.61 * * *$ & $-0.54 * * *$ & $-0.42^{* * *}$ & $-0.38^{* * *}$ & $-0.42^{* * *}$ & $-0.35^{* * *}$ \\
\hline Tapering & $0.48^{* * *}$ & $0.49 * * *$ & $0.40^{* * *}$ & $0.40^{* * *}$ & $0.39 * * *$ & $0.40^{* * *}$ \\
\hline \multicolumn{7}{|l|}{ 3-quarter-ahead } \\
\hline Quantitative Easing 1 & $-0.87 * * *$ & $-0.32^{* * *}$ & $-0.54 * * *$ & $-0.19 *$ & 0 & 0 \\
\hline Quantitative Easing 2 & $-0.76^{* * *}$ & $-0.70^{* * *}$ & $-0.54 * * *$ & $-0.51 * * *$ & $-0.53 * * *$ & $-0.44 * * *$ \\
\hline Maturity Extension Program & $-0.93 * * *$ & $-0.92^{* * *}$ & $-0.71 * * *$ & $-0.70 * * *$ & $-0.59 * * *$ & $-0.54 * * *$ \\
\hline Quantitative Easing 3 & $-0.60 * * *$ & $-0.53 * * *$ & $-0.45^{* * *}$ & $-0.41 * * *$ & $-0.45^{* * *}$ & $-0.38^{* * *}$ \\
\hline Tapering & $0.45^{* * *}$ & $0.46^{* * *}$ & $0.35^{* * *}$ & $0.35^{* * *}$ & $0.36^{* * *}$ & $0.38^{* * *}$ \\
\hline Controls & $\mathrm{NO}$ & YES & $\mathrm{NO}$ & YES & $\mathrm{NO}$ & YES \\
\hline
\end{tabular}

The table reports the estimation results for the 10-year treasury, AAA and BAA bonds, according to different estimation procedures. Results in Column (1), (3), and (5) are obtained by estimating a regression model where the only explanatory variables are the policy event dummy. Columns (2), (4), and (6) are obtained by estimating the model with the event dummies augmented with the additional control variables. Newey-West standard errors are used in the estimation. Sample: 1996q1-2015q1. The asterisks indicate the level of statistical significance: $* \mathrm{p}<0.1, * * \mathrm{p}<0.05$, *** $\mathrm{p}<0.01$ 


\section{Appendix}

The appendix checks the robustness of the results over alternative estimation methods and model specifications. Results are reported in Table A.1.

The deviations from the benchmark model specified in equation (2) in the main text are three. First, the model is estimated with the highest degree of cross-sectional heterogeneity. More specifically, the model is estimated separately for each individual (columns 1, 3, and 7). The results are then aggregated via mean-group (see Pesaran and Smith, 1995).

Second, the benchmark model is augmented with individual fixed effects (columns 2, 5, and 8). The fixed effects control for all possible time-invariant (both observable and non-observable) characteristics of the forecasters and are included to account for the fact that some forecasters might be present only during a short period, which could be characterized by movement of the yields in the same direction. Fixed effects are also useful to account for persistent biases that might arise from non-rationality, distorted incentives or specificities of the loss functions of individual forecasters. We have not used this specification as our benchmark model as it implies that forecasts of yields might have a trend. Moreover, fixed effects are not statistically significant and results are confirmed when they are removed from the model.

Third, the model is estimated by adding as additional controls the surprise component of a large set of market moving macroeconomic data that are released during the inter-SPF quarter (see Section 2). Since the frequency of macroeconomic date releases is higher that the frequency of the survey, for each macroeconomic indicator the news is aggregated by cumulating all the news associated with each release between consecutive surveys.

Overall, the results obtained with the different specifications do not differ substantially from the one presented in the main text. This indicates that the findings reported in the paper are very robust to the estimation method used and to the model specification chosen. 
Table A.1: Robustness analysis on the effect of non-standard measures on bond yields

\begin{tabular}{|c|c|c|c|c|c|c|c|c|c|}
\hline & \multicolumn{3}{|c|}{ 10-year Treasury Bond } & \multicolumn{3}{|c|}{ AAA Corporate Bond Yield } & \multicolumn{3}{|c|}{ BAA Corporate Bond Yield } \\
\hline & (1) & (2) & (3) & (4) & (5) & (6) & (7) & (8) & (9) \\
\hline \multicolumn{10}{|l|}{ current-quarter } \\
\hline Quantitative Easing 1 & $-0.32 * * *$ & $-0.51^{* *}$ & $-0.57^{* *}$ & $-0.44 * * *$ & $-0.40 * * *$ & $-0.43^{* * *}$ & - & - & - \\
\hline Quantitative Easing 2 & $-0.60 * * *$ & $-0.60 * * *$ & $-0.69 * * *$ & $-0.25^{* * *}$ & $-0.30 * * *$ & $-0.31 * * *$ & $-0.19 * * *$ & $-0.20 * * *$ & $-0.33^{* * *}$ \\
\hline Maturity Extension Program & $-0.86^{* * *}$ & $-0.78^{* * *}$ & $-1.05^{* * *}$ & $-0.70^{* * *}$ & $-0.62^{* * *}$ & $-0.95^{* * *}$ & $-0.20^{* * *}$ & $-0.35^{* * *}$ & $-0.28 * *$ \\
\hline Quantitative Easing 3 & $-0.66 * * *$ & $-0.51 * * *$ & $-0.56^{* * *}$ & $-0.62 * * *$ & $-0.32 * * *$ & $-0.43^{* * *}$ & $-0.51^{* *}$ & $-0.21 * *$ & $-0.45^{*}$ \\
\hline Tapering & $0.61^{* * *}$ & $0.65^{* *}$ & $0.43^{* *}$ & $0.44^{* * *}$ & $0.54^{* * *}$ & $0.27^{* * *}$ & $0.43^{* * *}$ & $0.63^{* * *}$ & $0.19^{*}$ \\
\hline \multicolumn{10}{|l|}{ 1-quarter-ahead } \\
\hline Quantitative Easing 1 & $-0.20 * * *$ & $-0.38^{* * *}$ & $-0.46^{* * *}$ & $-0.28^{* * *}$ & $-0.28 *$ & $-0.31 *$ & - & - & - \\
\hline Quantitative Easing 2 & $-0.66^{* * *}$ & $-0.65^{* * *}$ & $-0.78^{* * *}$ & $-0.36^{* * *}$ & $-0.40^{* * *}$ & $-0.46^{* * *}$ & $-0.17^{* * *}$ & $-0.28^{* * *}$ & $-0.42^{* * *}$ \\
\hline Maturity Extension Program & $-0.87 * * *$ & $-0.79 * * *$ & $-0.98^{* * *}$ & $-0.71^{* * *}$ & $-0.59 * * *$ & $-0.81 * * *$ & $-0.18^{* * *}$ & $-0.35^{* * *}$ & $-0.47^{* *}$ \\
\hline Quantitative Easing 3 & $-0.70 * * *$ & $-0.50^{* * *}$ & $-0.56^{* * *}$ & $-0.65^{* * *}$ & $-0.35^{* * *}$ & $-0.45^{* * *}$ & $-0.55^{* * *}$ & $-0.25^{* * *}$ & $-0.26^{*}$ \\
\hline Tapering & $0.59 * * *$ & $0.63^{* * *}$ & $0.42^{* * *}$ & $0.43^{* * *}$ & $0.49^{* * *}$ & $0.27^{* * *}$ & $0.39 * * *$ & $0.58^{* * *}$ & $0.38^{*}$ \\
\hline \multicolumn{10}{|l|}{ 2-quarter-ahead } \\
\hline Quantitative Easing 1 & $-0.18^{* * *}$ & $-0.32^{* *}$ & $-0.39 * *$ & $-0.28^{* * *}$ & $-0.18^{*}$ & $-0.18^{*}$ & - & - & - \\
\hline Quantitative Easing 2 & $-0.66^{* * *}$ & $-0.65^{* * *}$ & $-0.81 * * *$ & $-0.45^{* * *}$ & $-0.40^{* * *}$ & $-0.52 * * *$ & 0.01 & $-0.26^{* * *}$ & $-0.40^{* * *}$ \\
\hline Maturity Extension Program & $-0.94 * * *$ & $-0.82 * * *$ & $-0.97 * * *$ & $-0.78^{* * *}$ & $-0.62 * * *$ & $-0.85^{* * *}$ & $-0.22 * * *$ & $-0.37 * * *$ & $-0.68^{* *}$ \\
\hline Quantitative Easing 3 & $-0.64 * * *$ & $-0.46^{* * *}$ & $-0.50 * * *$ & $-0.62^{* * *}$ & $-0.31 * * *$ & $-0.37 * * *$ & $-0.47 * * *$ & $-0.22 * * *$ & $-0.13^{*}$ \\
\hline Tapering & $0.52 * * *$ & $0.56^{* * *}$ & $0.39 * * *$ & $0.37 * * *$ & $0.48^{* * *}$ & $0.31^{* * *}$ & $0.38^{* * *}$ & $0.57^{* * *}$ & $0.38^{*}$ \\
\hline \multicolumn{10}{|l|}{ 3-quarter-ahead } \\
\hline Quantitative Easing 1 & $-0.18^{* * *}$ & $-0.30 * * *$ & $-0.38^{* * *}$ & $-0.27^{* * *}$ & $-0.14^{*}$ & $-0.16^{*}$ & - & - & - \\
\hline Quantitative Easing 2 & $-0.62 * * *$ & $-0.64 * * *$ & $-0.81 * * *$ & $-0.51 * * *$ & $-0.43^{* * *}$ & $-0.58^{* * *}$ & $-0.16^{* * *}$ & $-0.32 * * *$ & $-0.42^{* * *}$ \\
\hline Maturity Extension Program & $-1.00 * * *$ & $-0.87^{* * *}$ & $-1.05^{* * *}$ & $-0.85^{* * *}$ & $-0.64 * * *$ & $-0.90 * * *$ & $-0.36^{* * *}$ & $-0.41 * * *$ & $-0.83^{* *}$ \\
\hline Quantitative Easing 3 & $-0.54 * * *$ & $-0.46^{* * *}$ & $-0.50 * * *$ & $-0.60^{* * *}$ & $-0.34 * * *$ & $-0.41 * * *$ & $-0.48^{* * *}$ & $-0.25^{* * *}$ & $0.06^{*}$ \\
\hline Tapering & $0.48^{* * *}$ & $0.53 * * *$ & $0.40^{* * *}$ & $0.28^{* * *}$ & $0.43^{* * *}$ & $0.31^{* * *}$ & $0.36^{* * *}$ & $0.55^{* * *}$ & $0.49 *$ \\
\hline SPF Controls & YES & YES & YES & YES & YES & YES & YES & YES & YES \\
\hline Bloomberg News & $\mathrm{NO}$ & $\mathrm{NO}$ & YES & NO & NO & YES & NO & NO & YES \\
\hline Fixed Effects & NO & YES & NO & NO & YES & NO & NO & YES & NO \\
\hline Mean-group & YES & NO & NO & YES & NO & NO & YES & NO & NO \\
\hline
\end{tabular}

The table reports the estimation results for the 10-year treasury, AAA and BAA bonds, according to different estimation procedures. Results in Column 1, 3, and 5 are obtained by estimating a regression model for each forecaster and then aggregating the results via mean-group. Results in columns 2, 4, and 6 are obtained by estimating the model with the fixed effects. Finally, figures in columns 3, 6, and 9 are obtained augmenting the benchmark model with the surprise component of a large set of macroeconomic releases (Bloomberg News). Newey-West standard errors are used in the estimation. Sample: 1996q1-2015q1. The asterisks indicate the level of statistical significance: ${ }^{*} \mathrm{p}<0.1, * * \mathrm{p}<0.05, * * *$ $\mathrm{p}<0.01$. 